\section{Diagnostic and immunoprophy- lactic applications of synthetic peptides in veterinary microbiology}

\author{
Paramasivam Saravanan, ${ }^{1}$ Satish Kumar ${ }^{2}$ \\ 'FMD Vaccine Centre, Indian Veterinary \\ Research Institute Campus, Hebbal, \\ Bangalore, Karnataka, India; ${ }^{2}$ National \\ Biotechnology Centre, Indian Veterinary \\ Research Institute, Izatnagar, Bareilly, \\ Uttar Pradesh, India
}

\section{Abstract}

Chemically synthesized peptides are considered as potential reagents for various applications in biological sciences. They mimic naturally occurring peptides or segments of proteins and have emerged as diagnostic reagents and safe immunogens in animal science. Carefully selected peptides resembling authentic epitopes serve as synthetic antigens in diagnostic tests. Synthetic peptide-based vaccines can elicit antibodies against animal pathogens. The early use of synthetic peptides as a vaccine for foot-andmouth disease stimulated interest in the development of peptide-based diagnostics and immunoprophylactics. The development of a peptide vaccine for canine parvovirus confirmed the usefulness of peptides as immunoprophylactics. Recently, the advent of the technology for the development of multiple antigenic peptides (MAPs) has provided a well-defined method for the production of highly immunogenic peptides and anti-peptide antibodies. Antibodies raised against major epitopes can be used in the detection of the native antigen (virus) in the enzymelinked immunosorbent assay (ELISA) and other tests, vindicating the usefulness of peptides for safe, chemically defined, non-infectious diagnostics and immunoprophylactics. This article focuses on the methods for selecting and preparing peptides for the predicted epitopes, their characterization and use, and the application of MAPs.

\section{Introduction}

Synthetic peptides are organic compounds composed of two or more amino acids linked together by peptide bonds and generated by chemical approaches. The tremendous advances in peptide synthesis have led to its application in diverse areas of drug design, chemotherapy, molecular immunology, bio- chemistry, oncology, vaccinology, and therapeutics. $^{1-9}$ The use of peptides in the study of immune response stems from the ability of peptides to mimic similar antigenic sequences naturally present in proteins. ${ }^{10}$

The cross-reactivity of antibodies raised against synthetic epitopes with the native protein has facilitated the development of a new generation of synthetic peptide vaccines, which are safe and potentially useful against a number of viral diseases, such as foot-andmouth disease (FMD), canine parvovirus (CPV), human immunodeficiency virus (HIV), and respiratory syncytial virus (RSV). ${ }^{5,11-14}$ Recently, the importance of peptide microarrays as potential diagnostic tools in high-throughput immunoassays is highlighted by Andresen and Bier. ${ }^{15}$

In practice, synthetic peptides corresponding to the major epitopes of larger polypeptides are used instead of intact proteins as reagents for the diagnosis of viral and autoimmune diseases. In addition, anti-peptide antibodies are useful reagents for isolating and characterizing the corresponding full length gene products. ${ }^{16}$ The identification and use of synthetic peptides as B-cell and T-cell recognition epitopes and their use as immune-potentiators in combination with other available vaccines have paved the way for designing multivalent immunoprophylactics. They are particularly beneficial in cases where full length protein is difficult to isolate or toxic, as epitopes devoid of the toxic portion can be superior antigenic molecules. ${ }^{17}$

The failure of some short peptides to elicit substantial immune responses owing to their small molecular weight has been overcome by preparing several copies of the peptide over the lysine core to create multiple antigenic peptides (MAPs). MAP technology is a novel and versatile strategy designed to overcome the limitations of carrier protein coupling and other methods to improve the immunogenicity of peptides. It has been possible to produce high titer anti-peptide sera and also immunogenic peptide vaccines for many pathogens using MAPs. ${ }^{8}$ Furthermore, the reactivity of the MAPs in immunological screening techniques is found to be as good as the native antigen and even better than some viral antigens, ${ }^{18}$ demonstrating their suitability as an alternative to the handling of infectious materials in diagnostic tests. This is recommended highly for avoiding the use of infectious viruses like FMDV, avian influenza (AI), and HIV in diagnostic assays and could reduce the associated risks.

In this report, we attempt to summarize current understanding of peptides, their synthesis, characterization, and use in veterinary microbiology.
Correspondence: Paramasivam Saravanan, Scientist Animal Biotechnology, FMD Vaccine Centre, Indian Veterinary Research Institute Campus, Hebbal, Bangalore, Karnataka: PIN-560 024, India. E-mail: drsaravana72@dr.com

Key words: synthetic peptides, antigen, vaccines, multiple antigenic peptides, anti-peptide antibody, diagnostics, immunoprophylactics.

Acknowledgements: the authors thank Prof. Ian Martin Jones, School of Biological Sciences, University of Reading, UK for critical review and suggestions for improvement of the manuscript.

Received for publication: 18 July 2009.

Revision received: 21 September 2009.

Accepted for publication: 25 September 2009.

This work is licensed under a Creative Commons Attribution 3.0 License (by-nc 3.0).

(OCopyright P. Saravanan, S. Kumar 2009

Licensee PAGEPress, Italy

Microbiology Research 2010; 1:e1

doi:10.4081/mr.2010.e1

\section{Prediction of antigenic determinants}

On immunization, a number of antibodies reactive to different epitopes of an antigen are produced. These epitopes, also known as antigenic determinants, are in an ordered conformation, present on the surface of the protein and generally hydrophilic in nature. Furthermore, these epitopes react independently with respective antibodies without causing conformational change in the antigen. By using these "rules of thumb" antigenic determinant analysis can be carried out using predictive analysis or algorithms for secondary structure, hydrophilicity, flexibility, surface probability, and antigenic index.

The prediction of the secondary structure of proteins helps in understanding their function and biological activity. Synthetic peptides also form different types of secondary structures like $\alpha$-helix, $\beta$-strands, $\beta$-turns, and random coils. All secondary structure prediction methods are based on the probability of a given residue adopting a particular secondary structure on the basis of statistical values from the known data. Several such methods are used in proteomics. Some of them are: (1) Chou and Fasman ${ }^{19}$ statistical method to predict secondary structures (strong helix former, helix breaker, strong beta sheet former, beta sheet breaker); (2) Kyte and Doolittle ${ }^{20}$ method to predict the surface probability (buried or exposed to the surface); (3) Hopp and Woods ${ }^{21}$ method based on the hydrophilicity scale; (4) Karpus and Schultz ${ }^{22}$ method based on the flex- 
ibility scale that predicts the backbone chain flexibility; and (5) surface probability index developed by Emini et al., ${ }^{23}$ which predicts the probability of a given amino acid to be found on the surface of a protein. Finally, Jameson and Wolf ${ }^{24}$ developed the antigenic index by combining all the above methods with due weighting for each characteristic. This method provides a surface contour value called the antigenic index and has been most successful in predicting the antigenic sites on a protein.

With developments in the field of computer science, various softwares are now available that take into account all these parameters to provide graphical representation of secondary structure predictions, e.g. DNASTAR (DNAStar Inc, Madison, WI, USA), and Preditop (Pellequer and Westhof, 1993). ${ }^{25}$ These softwares have been used to predict the antigenic sites of different pathogens, namely Leishmania antigen, ${ }^{26}$ the envelope glycoprotein of the Indian isolate of HIV- $1,{ }^{27}$ and viral coat proteins of the infectious bursal disease virus (IBDV), peste des petits ruminants virus (PPRV), and rinderpest virus (RPV) in our laboratory. ${ }^{18,28}$

\section{Peptide synthesis}

\section{History and developments in peptide synthesis}

About a century ago, Emil Fischer and Franz Hofmeister discovered that peptides and proteins are formed by amino acids linked by an amide bond. The field of peptide chemistry advanced rapidly after the discovery of the first peptide of biological importance, a tripeptide glutathione. ${ }^{29}$ Several peptides were prepared in large amounts like oxytocin, ${ }^{30}$ insulin, ${ }^{4}$ ribonuclease, ${ }^{31}$ and HIV type 1 protease ${ }^{32}$ with complete biological activity. The discovery of solid phase peptide synthesis (SPPS) by Merrifield $^{33}$ also accelerated the widespread use of peptides in biological research. Development of improved synthesis chemistry, automated instrumentation, purification, and analytical methods further contributed toward our ability to exploit the potential of synthetic peptides, and unambiguously proved their usefulness in immunology and therapeutics. ${ }^{9} \mathrm{~A}$ brief history of developments in peptide chemistry has been described. ${ }^{17}$

\section{Methods}

Peptide synthesis can be divided into solution (liquid) phase and solid phase peptide synthesis. Although solution phase peptide synthesis could be used for large-scale manufacturing, it is not preferred because of unpredictable solubility, crystallization of the intermediates, the need to optimize reactions, lower yields, and often extensive purification procedures for each intermediate. ${ }^{34,35}$ These disadvantages have compelled scientists to adopt solid phase peptide synthesis (SPPS). The classical solution phase methodology of peptide synthesis has been reviewed by Finn and Hofmann, ${ }^{35}$ and Bodanszky and Bodanszky. ${ }^{34}$ SPPS is based on the sequential addition of $\alpha$-amino and functional side chain protected amino acids to an insoluble support. After removal of $\mathrm{N}$-terminal protection, the next protected amino acid is added using a coupling reagent and pre-activated amino acid derivative. The resultant peptide attached to the resin via a linker at its $\mathrm{C}$-terminus is cleaved in the last step with side chain deprotection, to yield a peptide in acid or amide form. Side chain protecting groups are chosen often so as to be cleaved simultaneously with detachment of the peptide from resin to make the synthesis easier.

\section{Chemistries}

In modern SPPS methods two chemistries, namely t-BOC and FMOC, are employed. In BOC-chemistry, the $\alpha$-amino group is being protected with t-butyloxycarbonyl (t-BOC or BOC) group, which is cleavable by trifluoro acetic acid (TFA), and hence side chain protecting groups need to be stable in TFA. Final side chain deprotection and cleavage of peptides thus requires stronger acids (hydrogen fluoride or trifluoromethane sulphonic acid) than TFA resulting in side reactions. FMOCchemistry is a more recent method, which involves the use of 9-fluorenylmethy-loxycarbonyl (FMOC) group as the $\alpha$-amino group protecting agent. This can be cleaved under mild basic conditions like $20 \%$ piperidine. The final side chain deprotection and cleavage of synthesized peptides can be done easily using TFA without any side reactions. Owing to these advantages FMOC chemistry has outclassed BOC chemistry making the synthesis of even 100 -mer peptides a reality and has led to the development of new methods for follow-up synthesis. $^{36}$

\section{Linker or spacer}

The most commonly used linker is 4-hydroxymethyl-phenylacetamidomethyl (PAM), which has anchoring-bond stability, selectivity for extended stepwise procedure, ${ }^{37}$ and serves as a satisfactory support for peptide synthesis. Although various dipeptides have been used as spacers in the combinatorial library approach, the glycine-glycine (Gly-Gly) spacer had been recommended as ideal. ${ }^{38}$ The advantages of the Gly-Gly spacer is that it projects the epitopic peptide away from the solid support thereby presenting it for antigen-antibody interaction in a specific manner useful for screening by solid phase enzyme-linked immunosorbent assay (ELISA) without affecting the conforma- tion of the epitope. The same spacer was used for the synthesis of peptides of epitopes of infectious bursal disease (IBD), peste des petitis ruminants (PPR) and rinderpest (RP) viruses successfully. ${ }^{18,28,39}$

\section{Coupling strategies}

The coupling reagent used earlier in SPPS was diclyclohexyl carbodiimide (DCCI), which was replaced by uranium salts: 2-(benzotriazol-1-yl)-1,1,3,3-tetra-methyluronium hexafluorophosphate (HBTU) and 1-hydroxybenzotriazole (HOBt), which were used to hasten the coupling reaction and to suppress the racemization.

\section{Solid support}

PAM beads used for peptide synthesis have the desired peptide anchoring on polystyrene beads through a stable amide bond ${ }^{37}$ so that they can be used repeatedly in ELISA screening, ${ }^{40}$ even with $1 \mathrm{mg}$ of PAM beads for each peptide. To maintain a distance between the epitope peptide and bead, the Gly-Gly peptide spacer was linked again to the PAM beads. For larger fragment synthesis using FMOC chemistry and also for preparing MAPs, Wang resin is preferred as it allows easier final cleavage of peptides from the solid support using TFA. ${ }^{8}$ Wang resin was used in our laboratory for preparing MAPs for IBD and PPR, which were highly reactive in ELISA and the Western blotting. ${ }^{18,28}$ Several other resins and solid supports have been used in SPPS. ${ }^{41}$ Different strategies and developments in the field of peptide synthesis have been extensively reviewed. ${ }^{1,741-43}$

\section{Purification of peptides}

Developments in instrumentation and protein purification protocols have resulted in the use of matrix-assisted laser desorption ionization-time of flight mass spectrometry (MALDITOF MS) and reverse phase high performance liquid chromatography (RP-HPLC) for analyzing the purity of peptides. The peptide binds to the column through hydrophobic interactions and is eluted by decreasing the ionic strength and increasing the hydrophobicity of the mobile phase. RP-HPLC is useful for monitoring the purity of simple peptides as well as MAPs and the presence of byproducts, for preparing large quantities of pure peptides sufficient for structure-activity relationship studies, ${ }^{17}$ and to find out the suitability of the peptide for raising anti-peptide antibodies. In addition, RP-HPLC has been used in amino acid analysis of synthesized peptides using various pico-tag chemistries, and hence has become an integral part of automated protein sequencing units adopting Edman's chemistry. 
The presence of respective amino acids was checked by hydrolysis of MAP using $6 \mathrm{~N} \mathrm{HCl}^{18}$

\section{Characterization of peptides with circular dichroism spectroscopy}

Circular dichroism (CD) spectroscopy helps in elucidating the conformational structure of molecules in solution. The basic principle in $\mathrm{CD}$ is the differential absorption of left and right circularly polarized light when it passes through molecules in solution. Different secondary structures such as $\alpha$-helices, $\beta$-sheets, $\beta$-turn, and random coils produce specific CD spectral data. This technique is widely used to determine the secondary structure of proteins as well as peptides. The data provided by CD spectroscopy, high resolution NMR, and fluorescence helped in establishing that peptides in solution adopt mixed conformations rather than random coils. ${ }^{10} \mathrm{CD}$ spectroscopy of peptides is performed also to define factors determining protein folding and stabilization of native structure. ${ }^{44}$

\section{Synthetic peptides as diagnostics}

Synthetic peptides are used in various areas, such as epitope mapping, characterization of monoclonal antibodies, and differentiation of continuous (sequential) from discontinuous epitopes. ${ }^{40}$

Peptides can produce antibodies when injected into animals. The ability of an antigen (peptide) to bind to an antibody is referred to as antigenicity. An antigen may comprise of Bcell and/or T-cell epitopes.

Epitope mapping can be done by the peptide library approach or by predicting antigenic determinants using software. ${ }^{8}$ The former strategy involves construction of a library of overlapping peptides representing the entire protein and testing all the peptides by enzyme immunoassay (EIA). The latter strategy involves synthesis and analysis of fewer peptides, and was successfully used in our laboratory for the prediction and synthesis of antigenic determinants on VP2 and VP3 of IBDV, ${ }^{18,39}$ and N protein of PPRV and RPV. ${ }^{28}$ The overlapping peptide library approach has been employed to identify the immunodominant epitopes of the major outer protein of Chalamydia trachomatis, ${ }^{45}$ VP7 protein of the blue tongue virus, ${ }^{46} 15 \mathrm{kDa}$ lipoprotein of Treponema pallidum, ${ }^{47}$ variable surface antigen of Borellia burgdorferi, ${ }^{48}$ p67 protein of Theileria parva, ${ }^{49}$ and BP26 protein of Brucella

\section{melitensis. ${ }^{50}$}

In virology, synthetic peptides are viewed as chemically defined, safe, specific, and reusable reagents, which have proved to be an alternative to viral antigens in disease diagnosis..$^{18,39,51}$ Synthetic peptide representing 81-106 aa of the envelope glycoprotein of the equine arteritis virus (EAV) was conjugated to ovalbumin to develop an ELISA for the detection of antibodies in serum samples of horses. ${ }^{52}$ A peptidebased ELISA was developed for sero-diagnosis of enterovirus infections in humans. ${ }^{53}$ A cluster of immunodominant epitopes in the C-terminus of viral structural capsid protein or tegument protein (VCAp18) of the Epstein-Barr Virus (EBV), when combined into a single synthetic peptide, demonstrated a greater potential for diagnosis in ELISA. ${ }^{54}$ Synthetic peptides derived from the surface glycoprotein gp90 of the equine infectious anemia virus, ${ }^{55}$ the attachment protein $\mathrm{G}$ of $\mathrm{RSV}^{56}$ hepatitis $\mathrm{C}$ virus, ${ }^{57}$ bovine leukemia virus, ${ }^{58} \mathrm{~N}$ protein of PPRV, ${ }^{28}$ and VP2 and VP3 proteins of IBDV ${ }^{18,39}$ have all been used as antigens in various EIA for sero-diagnosis. Immunodominant epitopes on the N protein of PPRV were identified using the overlapping bead-bound decapeptide library, which could be useful for the differentiation of RP and PPR antibodies in serum. ${ }^{28}$ The immunogenic epitopes on the VP2 and VP3 proteins of IBDV were evaluated for antigenicity, immunogenicity, and reactivity in ELISA. ${ }^{18,39}$ In addition, a peptide was used as a protein or nucleic acid delivery molecule in the IBDV model. ${ }^{3}$

Some of the promising peptide-based antigen-antibody detection kits for PPRV and FMDV have been patented (S.Kumar personal communication for PPRV; United Biomedical, Inc. $(U B I)$ for $\left.F M D V^{59}\right)$. Furthermore, the antipeptide antibody produced against the peptide could be used in diagnostic assays for detecting the antigen.

In parasitology, Plasmodium falciparum exoantigen peptide sequence of $70 \mathrm{kDa}$, when synthesized and constructed as a copolymer, was capable of inducing antibodies that were reactive with native malarial protein, indicating its potential as an immunogen and diagnostic agent. ${ }^{60}$ A synthetic peptide for $89-122$ of Echinococcus granulosus showed high binding sensitivity and specificity for screening infected patient sera, and could serve as an antigen in the diagnosis and surveillance of hydatidosis. ${ }^{61}$ Synthetic peptides have found use also in the diagnosis of cystic hydatidosis, ${ }^{62}$ Babesia equi infection in horses, ${ }^{63}$ and visceral leishmaniasis. $^{26}$

In bacteriology, peptides are used for the detection of antibodies to Chlamydia trachomatis in clinical specimens ${ }^{64}$ where they confirmed that the peptide-based EIA kit was superior to the other kits. A cocktail of peptides was used for the differentiation of Myco- bacterium bovis infected from bacillus Calmette-Guérin (BCG)-vaccinated cattle. ${ }^{65}$ Nevertheless, some peptides showed antimicrobial or antibiotic activity. ${ }^{66}$

It is evident that peptides could serve as alternative reagents for developing diagnostics and for differential diagnosis of closely related diseases.

\section{Anti-peptide antibodies as diagnostic reagents}

An important application of short synthetic peptides is to generate protein reactive (antipeptide) antibodies that possess the ability to recognize native protein in immunoassays. Anti-peptide antibodies are used to identify and quantify proteins, and as reagents in immunoprecipitation, immunohistochemisty, or Western blotting. ${ }^{10}$ Production of a highly specific anti-peptide antibody involves synthesizing peptides, coupling to carrier proteins, and immunization. However, the carriers also induce antibody production, which can be eliminated by the use of MAP.

Prominently, anti-peptide antibodies could be used to detect antigen to confirm a disease outbreak. Dechamma et al. ${ }^{28}$ produced antipeptide antibodies using MAP to the 454-472 region of N protein of PPRV, which could detect the viral antigen in indirect ELISA, immunocapture ELISA, dot-blot ELISA, and Western blot. Similarly purified anti-peptide antibodies raised against the MAPs of VP3 protein of IBDV detected the native virus in ELISA. ${ }^{39}$ Thus the peptides and anti-peptide antibodies, besides being safe, chemically defined, and noninfectious reagents, offer a two-pronged approach for animal disease diagnosis. Further anti-peptide antibodies could alleviate the fear of handling the infectious agents like severe acute respiratory syndrome (SARS), AI, and HIV in diagnostic assays. Anti-viral peptide antibodies could be produced in a short time and resemble monoclonal antibodies as they are produced mostly against a single epitope.

\section{Peptide-based vaccines}

The eradication of most of life-threatening diseases could be achieved with the use of vaccines. Vaccines consist of killed or attenuated (genetically modified) pathogens that induce immunity when injected with adjuvants. New generation vaccines include recombinant antigens expressed in various systems and peptides. The benefits of using peptide vaccines over whole organism vaccines include safety, no vaccine-related disease outbreaks, no 
reversion to virulence, no danger of inefficient inactivation, and that they are economical when compared to growing organisms in media to produce the vaccine.

Another major problem with whole organism vaccines is that the survival strategy of most pathogens depends on antigenic variability, the capacity to alter the antigenic sites by genetic or phenotypic mechanisms in the form of genetic shift or drift as in influenza and rhinoviruses. ${ }^{17}$ Thus, new vaccines to the same pathogen must be developed continuously and new strains need to be included in the preparation of a vaccine for a specific pathogen as in FMDV.

Peptide vaccines provide two ways for coping with antigenic variation. First, since linear synthetic epitopes are fairly easily prepared, mutations once located can be readily incorporated into the synthesis. Second and perhaps of greater importance, invariant antigenic sequences of the pathogen can be utilized to promote longer-lasting immunity.

Investigation of peptide vaccines has largely centered on antiviral agents, such as for FMD, $\mathrm{CP}$, hepatitis $\mathrm{C}$, influenza, polio, and HIV viruses. ${ }^{5,14,51,67,68}$ Apart from these, antibacterial peptide vaccines are of interest as, for example, diphtheria and cholera toxins as well as antiparasitic immunogens for the prevention of malaria. ${ }^{6,8}$

For FMD, Dimarchi et al. ${ }^{67}$ reported a high neutralizing antibody titer and protection against live virus challenge of cattle following single vaccination with a synthetic peptide representing 141-158 and 200-213 of VP1 of FMDV 01K. Since there are seven types and many subtypes of FDMV, it is important to include more than one type to provide protection in a particular area. It might be possible to immunize animals against all seven serotypes of FMDV using linear peptides of different serotypes synthesized in tandem, as demonstrated by Francis et al. ${ }^{13}$ Venkataramanan et $a l .{ }^{68}$ confirmed that a peptide for the 136-151 region of VP1 of FMDV A22 produced neutralizing antibody and complete protection in hill bulls and was as immunogenic as the conventional gel vaccine. Immunization of cattle with a dimeric 10-mer peptide for VP1 of FMDV 01 Campos induced a long lasting cellular and neutralizing antibody response..$^{69}$

Despite impressive progress in FMD, no effective peptide comparable to the inactivated vaccine has been produced yet owing to the discontinuous nature of many epitopes and the involvement of more than one antigenic site. These problems can be overcome by including more than one antigenic site in peptide formulation and by designing peptides that functionally mimic the discontinuous epitopes of FMDV. ${ }^{16}$

Two overlapping 15-mer peptides for the Nterminus of VP2 of CPV induced long-lasting immunity when used with Freund's adjuvant or aluminum hydroxide, and is the first successful peptide vaccine reported in dogs. ${ }^{5}$ Ohishi $e t$ $a l^{58}$ reported that a 20 -mer peptide for $98-117$ of the envelope glycoprotein gp151 of the bovine leukemia virus induced cell-mediated immunity (CMI) in mice. Similarly the peptide vaccines for RSV, ${ }^{11}$ bovine rota virus ${ }^{70}$ and other viruses were produced. ${ }^{2}$

It is important to admit that in spite of tremendous advances in peptide vaccines, not a single product emerged in the market largely owing to the fact that most viral neutralizing epitopes are discontinuous.

\section{Conjugated peptides}

Peptides often fail to elicit an immune response owing to their small size, as even a 10 -mer peptide will be $1.1 \mathrm{kDa}$ (one amino acid, $M W=110 \mathrm{Da}$ ). The minimum size of a protein to act as an immunogen is $5-10 \mathrm{kDa}$, meaning that a 40 - to 100 -mer peptide is needed, which is very difficult to define in terms of reactivity and difficulty to prepare. Peptides are conjugated with carrier proteins [bovine serum albumin (BSA)], ovalbumin (OVA), or key-hole limpet hemocyanin (KLH) to make them bulkier and immunogenic.

Conjugation of peptides to carrier protein involves the use of functional agents like glutaraldehyde, ${ }^{71}$ (1-ethyl-3-(dimethylaminopropyl) carbodiimide (EDAC), and m-maleimido-benzoyl-N-hydroxysuccimide ester (MBS). ${ }^{72}$ These methods are popular, inexpensive, and effective.

\section{Multiple antigenic peptides}

The poorly immunogenic nature of peptides can be circumvented by coupling to a carrier protein but the limitations are: only a small portion of the peptide antigen is represented in the whole peptide-carrier conjugate, chemical ambiguity in antigen composition and structure, irrelevant epitopes, carrier-induced epitope suppression or toxicity. These drawbacks can be overcome by use of the MAP system developed by Tam, ${ }^{8}$ and Posnett et al. ${ }^{73}$

MAPs can be prepared by FMOC or t-BOC chemistry. A MAP has three structures: an amino acid bound to a resin, an inner core matrix consisting of layers of lysine, and a surface layer of peptide antigens attached to the lysine inner core matrix. MAPs can be prepared by direct or indirect approaches. In the direct approach, the MAP core is formed by attaching several layers of lysine to the resin containing the amino acid (alanine). Then the peptide is assembled onto this MAP core matrix. In the indirect approach, the MAP core and peptide are prepared and purified separately, and then linked together to form the complete MAP. ${ }^{8}$

In MAP preparation the $\mathrm{C}$ - or $\mathrm{N}$-terminal or hydrophilic region of the antigen that contains T- and B-cell epitopes is preferred. Furthermore, two different antigens can be combined in a MAP by selective blocking of half of the reactive groups of lysine during synthesis, besides making inbuilt adjuvants.

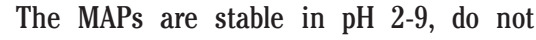
require cold chain, can be stored or transported in lyophilized powder without loss of biological activity, and are pure and immunologically focused. They can provide peptide as more conformationally defined epitopes and help in adsorption to a solid surface.

MAPs are used in immunoassays for serodiagnosis of malaria, ${ }^{74}$ cirrhosis,${ }^{75}$ hepatitis $\mathrm{C}$ virus, ${ }^{51}$ infectious bronchitis $,{ }^{76} \mathrm{PPR},{ }^{28}$ and IBD. ${ }^{18}$ In addition, MAPs and anti-peptide antibodies produced for VP2 and VP3 proteins of IBDV were evaluated for the binding ability to replace viral antigen and for their diagnostic potential. ${ }^{18}$

The MAP approach has been used also in the preparation of experimental vaccines, against hepatitis $\mathrm{B},{ }^{17}$ malaria, ${ }^{6} \mathrm{FMD},{ }^{77}$ and HIV. ${ }^{14}$

In general, the crude MAPs are pure enough for many purposes (e.g. for production of antisera). When highly purified MAPs are required (e.g. vaccines for humans) it is necessary to purify the crude product to near homogeneity by dialysis, gel-filtration chromatography, RPHPLC, and HPLC.

The multimeric nature of the MAP construct overcomes the drawbacks of simple peptides in EIA, and provides an increased surface binding property and reproducibility as they bind stronger than the monomer by allowing multiple points of contact. ${ }^{39,75}$

MAP technology represents a novel, versatile approach for raising anti-peptide antibodies, which in turn would be of paramount importance for diagnostic assays. ${ }^{73}$ Anti-peptide antibodies could be produced using immunization protocols in rabbits and the sera should be screened by indirect ELISA. It has been clearly demonstrated that MAP technology could possibly serve as a better antigen or immunogen than can their respective simple peptides.

\section{Conclusions}

Synthetic peptides could help in the delineation of epitopes, which in turn would be of use in the diagnosis of important pathogens. Peptides may slowly replace the conventional virulent pathogens (viruses) as antigens as they are safe, specific, and chemically defined 
reagents for disease diagnosis, and could assist in the reduction in disease outbreaks. Furthermore, repeated use of the bead-bound peptides could reduce the cost and become an economically feasible test system.

It is evident from the above discussion that synthetic peptide vaccines based on MAPs would be an ultimate vaccine that could match the classical vaccines with respect to efficacy for viruses like FMDV and CPV. It was suggested also that for viruses which have limited antigenic variation or linear neutralizing epitopes, synthetic peptide vaccines could be the ideal vaccine in the near future. The anti-peptide antibodies specific to epitopic peptide could be produced easily using MAPs, which will alleviate the need for conjugation and could be used as such for disease diagnosis.

Although there are no commercially available synthetic peptide-based diagnostics or immunoprophylactics, in the near future synthetic peptide-based antigens and immunogens for highly pathogenic organisms will become a reality, particularly to handle viruses like FMDV in disease-free countries, and will be a great benefit to mankind in the field of animal healthcare.

\section{References}

1. Arnon R, Horwitz RJ. Synthetic peptides as vaccines. Curr Opin Immunol 1992;4:449-53.

2.Azizi A, Diaz-Mitoma F. Viral peptide immunogens: current challenges and opportunities. J Pept Sci 2007;13:776-86.

3. Bais MV, Kumar S, Tiwari AK, et al. Novel Rath peptide for intracellular delivery of protein and nucleic acids. Biochem Biophys Res Commun 2008;370:27-32.

4. Katsoyannis PG, Tometsko A, Zalut C. Insulin peptides. XII. Human insulin generation by combination of synthetic A and B chains. J Am Chem Soc 1966;88:166-7.

5. Langeveld JP, Casal JI, Osterhaus AD, et al. First peptide vaccine providing protection against viral infection in the target animal: studies of canine parvovirus in dogs. J Virol 1994;68:4506-13.

6. Pessi A, Bianchi E, Chiappinelli L, et al. Multiple antigen peptides (MAPs) as candidate vaccines against malaria. Parassitolo gia 1991;33:79-84.

7. Sabatino G, Papini AM. Advances in automatic, manual and microwave-assisted solid-phase peptide synthesis. Curr Opin Drug Discov Devel 2008;11:762-70.

8. Tam JP. Synthetic peptide vaccine design: synthesis and properties of a high-density multiple antigenic peptide system. Proc Natl Acad Sci USA 1988;85:5409-13.

9. Zaccaro L, Del Gatto A, Pedone C, et al. Peptides for tumour therapy and diagnosis: current status and future directions. Curr Med Chem 2009;16:780-95.

10. Lerner RA. Tapping the immunological repertoire to produce antibodies of predetermined specificity. Nature 1982;299:593-6.

11. Bastien N, Trudel M, Simard C. Complete protection of mice from respiratory syncytial virus infection following mucosal delivery of synthetic peptide vaccines. Vaccine 1999; 17:832-6.

12. Bittle JL, Houghten RA, Alexander H, et al. Protection against foot-and-mouth disease by immunization with a chemically synthesized peptide predicted from the viral nucleotide sequence. Nature 1982;298:30-3.

13. Francis MJ, Hastings GZ, Clarke BE, et al. Neutralizing antibodies to all seven serotypes of foot-and-mouth disease virus elicited by synthetic peptides. Immunology 1990;69:171-6.

14. Nardelli B, Lu YA, Shiu DR, et al. A chemically defined synthetic vaccine model for HIV-1. J Immunol 1992;148:914-20.

15. Andresen H, Bier FF. Peptide microarrays for serum antibody diagnostics. Methods Mol Biol 2009;509:123-34.

16. Van Regenmortel MH, Choulier L. Recognition of peptides by antibodies and investigations of affinity using biosensor technology. Comb Chem High Throughput Screen 2001; 4:385-95.

17. Gutte B, ed. Peptides: synthesis, structure and applications. San Diego: Academic Press, 1995, pp 456-70.

18. Saravanan P, Kumar S, Kataria JM. Use of multiple antigenic peptides related to antigenic determinants of infectious bursal disease virus (IBDV) for detection of antiIBDV-specific antibody in ELISA--quantitative comparison with native antigen for their use in serodiagnosis. J Immunol Methods 2004;293:61-70.

19. Chou PY, Fasman GD. Prediction of the secondary structure of proteins from their amino acid sequence. Adv Enzymol Relat Areas Mol Biol 1978;47:45-148.

20. Kyte J, Doolittle RF. A simple method for displaying the hydropathic character of a protein. J Mol Biol 1982;157:105-32.

21. Hopp TP, Woods KR. Prediction of protein antigenic determinants from amino acid sequences. Proc Natl Acad Sci USA 1981; 78:3824-8.

22. Karplus PA, Schultz GE. Prediction of chain flexibility in proteins. Naturwissenschaften 1985;72:212-22.

23. Emini EA, Hughes JV, Perlow DS, et al. Induction of Hepatitis A virus neutralizing antibody by a virus-specific synthetic peptide. J Virol 1985;55:836-9.

24. Jameson BA, Wolf $H$. The antigenic index: a novel algorithm for predicting antigenic determinants. Comput Appl Biosci 1988; 4:181-6.
25. Pellequer JL, Westhof E. PREDITOP: a program for antigenicity prediction. J Mol Graph 1993;11:191-2, 204-10.

26. Fargeas C, Hommel M, Maingon R, et al. Synthetic peptide-based enzyme-linked im munosorbent assay for serodiagnosis of visceral leishmaniasis. J Clin Microbiol 1996; 34:241-8.

27. Mohabatkar H, Kar SK. Prediction of exposed domains of envelope glycoprotein in Indian HIV-1 isolates and experimental confirmation of their immunogenicity in humans. Braz J Med Biol Res 2004;37:67581.

28. Dechamma HJ, Dighe V, Kumar CA, et al. Identification of T-helper and linear B epitope in the hypervariable region of nucleocapsid protein of PPRV and its use in the development of specific antibodies to detect viral antigen. Vet Microbiol 2006;118:201-11.

29. Harington CR, Mead TH. Synthesis of glutathione. Biochem J 1935;29:1602-11.

30. Du Vigneaud V, Ressler C, Trippett S. The sequence of amino acids in oxytocin, with a proposal for the structure of oxytocin. J Biol Chem 1953;205:949-57.

31. Hirschmann R, Nutt RF, Veber DF, et al. Studies on the total synthesis of an enzyme. $\mathrm{V}$. The preparation of enzymatically active material. J Am Chem Soc 1969;91:507-8.

32. Nutt RF, Brady SF, Darke PL, et al. Chemical synthesis and enzymatic activity of a 99residue peptide with a sequence proposed for the human immunodeficiency virus protease. Proc Natl Acad Sci USA 1988;85:712933.

33. Merrifield RB. Solid phase peptide synthesis I. The synthesis of tetrapeptide. J Am Chem Soc 1963;85:2149-54.

34. Bodanszky M, Bodanszky A. Principles of peptide synthesis: In: The practice of peptide synthesis. Berlin: Springer-Verlag, 1984.

35. Finn FM, Hofmann K. The synthesis of peptides by solution methods with emphasis on peptide harmones. In: Proteins. Vol. II, 3rd edn. Neurath H and Hill RL, editors. New York: Academic Press, 1976;105-253.

36. Newcomb WS, Deegan TL, Miller W, et al. Analysis of 9-fluorenylmethoxycarbonyl (FMOC) loading of solid-phase synthesis resins by gas chromatography. Biotechnol Bioeng 1998;61:55-60.

37. Mitchell AR, Kent SBH, Engelhard M, et al. A new synthetic route to test butyloxycarbony aminoacyl-4-(0xymethyl) phenylacetamidomethyl-resin, an improved support for solid phase peptide synthesis. J Org Chem 1978;43:2845-52.

38. Yu Z, Chu Y. Combinatorial epitope search: pitfalls of library design. Bioorg Med Chem Letters 1997;7:95-8.

39. Saravanan P, Satishkumar, Kataria JM, et al. Detection of infectious bursal disease virus by ELISA using an antipeptide antibody 
raised against VP3 region. Acta Virol 2004; 48:39-45.

40. Syu WJ, Kahan L. Characterization of antigenic structures by mapping on resin-bound epitope analogs. Methods Enzymol 1991; 203:295-300.

41. Fields CG, Fields GB. Solvents for solidphase peptide synthesis. Methods Mol Biol 1994;35:29-40.

42. Artherton E, Sheppard RC. Solid Phase Peptide Synthesis: Practical Approach. Rickwood D and Hames BD, eds. Oxford: IRL Press, 1989.

43. Grant GA. Synthetic peptides for production of antibodies that recognize intact proteins. Curr Protoc Immunol 2003;Ch.9:Unit 9.2.

44. Dyson HJ, Wright PE. Unfolded proteins and protein folding studied by NMR. Chem Rev 2004;104:3607-22.

45. Zhong GM, Brunham RC. Immunoaccessible peptide sequences of the major outer membrane protein from Chlamydia trachomatis serovar C. Infect Immun 1990;58:3438-41.

46. Du Plessis DH, Wang LF, Jordaan FA, et al. Fine mapping of a continuous epitope on VP7 of bluetongue virus using overlapping synthetic peptides and a random epitope library. Virology 1994;198:346-9.

47. Baughn RE, Demecs M, Taber LH, et al. Epitope mapping of B-cell determinants on the 15-kilodalton lipoprotein of Treponema pallidum (Tpp15) with synthetic peptides. Infect Immun 1996;64:2457-66.

48. Liang FT, Philipp MT. Epitope mapping of the immunodominant invariable region of Borrelia burgdorferi VlsE in three host species. Infect Immun 2000;68:2349-52.

49. Nene V, Gobright E, Bishop R, et al. Linear peptide specificity of bovine antibody responses to p67 of Theileria parva and sequence diversity of sporozoite-neutralizing epitopes: implications for a vaccine. Infect Immun 1999;67:1261-6.

50. Seco-Mediavilla P, Verger JM, Grayon M, et al. Epitope mapping of the Brucella melitensis BP26 immunogenic protein: usefulness for diagnosis of sheep brucellosis. Clin Diagn Lab Immunol 2003;10:647-51.

51. Simmonds P, Rose KA, Graham S, et al. Mapping of serotype-specific, immunodominant epitopes in the NS-4 region of hepatitis $\mathrm{C}$ virus (HCV): use of type-specific peptides to serologically differentiate infections with HCV types 1, 2, and 3. J Clin Microbiol 1993;31:1493-503.

52. Nugent J, Sinclair R, deVries AA, et al. Development and evaluation of ELISA procedures to detect antibodies against the major envelope protein $(\mathrm{G}(\mathrm{L}))$ of equine arteritis virus. J Virol Methods 2000 Nov;90(2):16783.

53. Cello J, Svennerholm B. Detection of enterovirus-specific total and polymeric IgA antibodies in serum using a synthetic peptide or heated virion antigen in ELISA. J Med Virol 1994;44:422-7.

54. Van Grunsven WM, Spaan WJ, Middeldorp JM. Localization and diagnostic application of immunodominant domains of the BFRF3encoded Epstein-Barr virus capsid protein. J Infect Dis 1994;170:13-9.

55. Ball JM, Rushlow KE, Issel CJ, et al. Detailed mapping of the antigenicity of the surface unit glycoprotein of equine infectious anemia virus by using synthetic peptide strategies. J Virol 1992;66:732-42.

56. Langedijk JP, Middel WG, Schaaper WM, et al. Type-specific serologic diagnosis of respiratory syncytial virus infection, based on a synthetic peptide of the attachment protein G. J Immunol Methods 1996;193:157-66.

57. Kotwal GJ. Routine laboratory diagnosis of hepatitis C virus infection. J Hepatol 1993; 17:S83-9.

58. Ohishi K, Kabeya H, Amanuma $\mathrm{H}$, et al. Induction of bovine leukaemia virus Envspecific Th-1 type immunity in mice by vaccination with short synthesized peptide-liposome. Vaccine 1996;14:1143-8.

59. UBI Synthetic Peptide-based Diagnostic Tests and Vaccines for Foot-and-Mouth Disease. Available at www.unitedbiomedical.com, accessed on 12.5.2009.

60. James MA, Montenegro-James S, FajfarWhetstone C. Immunogenicity and antigenic reactivity of a carrier-free synthetic peptide complex derived from a $70-\mathrm{kDa}$ Plasmodium falciparum exoantigen. Parasitol Res 1993;79:501-7.

61. Chamekh M, Gras-Masse H, Bossus M, et al. Diagnostic value of a synthetic peptide derived from Echinococcus granulosus recombinant protein. J Clin Invest 1992;89: 458-64.

62. Barbieri M, Fernandez V, Gonzalez G, et al. Diagnostic evaluation of a synthetic peptide derived from a novel antigen $B$ subunit as related to other available peptides and native antigens used for serology of cystic hydatidosis. Parasite Immunol 1998;20:5161.

63. Hanafusa Y, Sudo T, Sako Y, et al. Identification of $B$ cell epitopes of a $30 \mathrm{kDa}$ Babesia equi merozoite surface protein. $\mathrm{J}$ Vet Med Sci 1998;60:563-7.

64. Ouchi K, Hasegawa K, Maki R, et al. Evaluation of a synthetic peptide-based species specific EIA kit for detection of antibodies to Chlamydia trachomatis with clinical specimens. Kansenshogaku Zasshi 1998;72:249-57.

65. Vordermeier HM, Whelan A, Cockle PJ, et al. Use of synthetic peptides derived from the antigens ESAT-6 and CFP-10 for differential diagnosis of bovine tuberculosis in cattle. Clin Diagn Lab Immunol 2001;8:571-8.

66. Noga EJ, Silphaduang U, Park NG, et al. Piscidin 4, a novel member of the piscidin family of antimicrobial peptides. Comp Biochem Physiol B Biochem Mol Biol 2009;152:299-305.

67. DiMarchi R, Brooke G, Gale C, et al. Protection of cattle against foot-and-mouth disease by a synthetic peptide. Science 1986;232:639-41.

68. Venkataramanan R, Rai DV, Pattnaik B, et al. Protective antibody response to a synthetic peptide foot-and-mouth disease vaccine in cattle. Ind J Ani Sci 1994;64:9-13.

69. Zamorano PI, Wigdorovitz A, Perez Filgueira $\mathrm{DM}$, et al. Induction of anti foot-and-mouth disease virus $\mathrm{T}$ and $\mathrm{B}$ cell responses in cattle immunized with a peptide representing ten amino acids of VP1. Vaccine 1998; 16:558-63.

70. Ijaz MK, Nur EKMS, Dar FK, et al. Inhibition of rotavirus infection in vitro and in vivo by a synthetic peptide from VP4. Vaccine 1998;16:916-20.

71. Baron MH, Baltimore D. Antibodies against the chemically synthesized genome-linked protein of poliovirus react with native virusspecific proteins. Cell 1982;28:395-404.

72. Bauminger S, Wilchek M. The use of carbodiimides in the preparation of immunizing conjugates. Methods Enzymol 1980;70: 151-9.

73. Posnett DN, McGrath H, Tam JP. A novel method for producing anti-peptide antibodies. Production of site-specific antibodies to the T cell antigen receptor beta-chain. J Biol Chem 1988;263:1719-25.

74. Habluetzel A, Pessi A, Bianchi E, et al. Multiple antigen peptides for specific detection of antibodies to a malaria antigen in human sera. Immunol Lett 1991;30:75-80.

75. Briand JP, Barin C, Van Regenmortel MH, et al. Application and limitations of the multiple antigen peptide (MAP) system in the production and evaluation of anti-peptide and anti-protein antibodies. J Immunol Methods 1992;156:255-65.

76. Jackwood MW, Hilt DA. Production and immunogenicity of multiple antigenic peptide (MAP) constructs derived from the S1 glycoprotein of infectious bronchitis virus (IBV). Adv Exp Med Biol 1995;380:213-9.

77. Francis MJ, Hastings GZ, Brown F, et al. Immunological evaluation of the multiple antigen peptide (MAP) system using the major immunogenic site of foot-and-mouth disease virus. Immunology 1991;73:249-54. 